$<$ Heather De Forest $^{1}$, Luanne Freund ${ }^{2}$, Aleha McCauley ${ }^{2}$, Heather L. O'Brien ${ }^{2}$ and Suzanne Smythe ${ }^{1}>$

$<$ Simon Fraser University $>,<$ Vancouver, BC, Canada $>$

$<^{2}$ University of British Columbia $>,<$ Vancouver, BC, Canada $>$

\title{
Building infrastructures for university-community knowledge exchange: The Role of Information Professionals and Literacy Educators (Panel)
}

\begin{abstract}
Résumé:
This panel argues that information professionals and literacy educators play an important bridging role between universities and community groups and stakeholders. We describe the context of universitycommunity knowledge exchange, which is increasingly expected, but remains under-supported and under-theorised, and consider new opportunities that exist to support and build capacity in researchers and communities to co-create, share, and use information. We focus on the training and professional development needed to position information professionals and literacy educators as knowledge brokers, and innovative projects that demonstrate their value and potential in this role.
\end{abstract}

\section{Problem Statement}

Community engagement, knowledge exchange $(\mathrm{KE})^{1}$, and open access to research data and products feature heavily in Canadian universities' strategic plans and (inter)national funding agencies' policies. There are growing expectations that university research be accountable to and benefit Canadians. Drivers of these movements include: 1) increased computational power and new media that are changing the nature of scholarly outputs (e.g., data sets, interactive and social media) and their evaluation (e.g., altmetrics); 2) growing concerns about the social and economic value of research and transparency in research practices (Acord \& Harley 2013); and 3 ) the development of principles and practices to create more equitable relations between researchers and research participants, in particular among First Nations, Métis, Inuit and Indigenous peoples in Canada.

\footnotetext{
${ }^{1}$ Shaxson, Bielak, Ahmed, Brien et al. (2012) use the term "KStar" or "K*" as an "overarching concept" and "useful shorthand" (Foreword) for knowledge translation, knowledge mobilization, knowledge exchange, and so on. We use " knowledge exchange" in this proposal to reflect: reciprocity between researchers and knowledge users, evidence-based decision making, and the alignment research processes and outcomes with community needs and priorities (CMHA, 2018). KE is an appropriate term to describe the range of activities that occur in knowledge creation and sharing in diverse contexts and geographies.
} 
Despite requirements, incentives and ethical imperatives, scholarly practices have been slow to change. Entrenched promotion and tenure systems within universities continue to view community-engaged scholarship as part of service rather than research, privileging publication quantity and de-incentivizing public scholarship and non-traditional modes of dissemination (Alperin, et al. 2018; Harley et al. 2010). In addition to institutional barriers, scholars have limited time, tools and knowledge about open access publishing (Morrison 2013) and new genres of scholarly output, e.g., the publishing of data sets, social and visual media, lay summaries (Harley et al. 2010) and participatory research. Many researchers are trained in end-of-project dissemination (e.g., writing journal articles) (Harley et al. 2010), but fewer are practicing integrated KE, which involves stakeholders in varied capacities throughout the research process.

Integrated KE promises many benefits: higher quality research that is more targeted to stakeholder needs, empowered research participants, increased accountability, transparency, and democracy in research, and greater uptake and application of research findings (Esmail, et al. 2015). In the past several years, "knowledge brokers" have become an integral component of research teams, particularly in health. Knight and Lightowler define brokers or "knowledge exchange professionals" in university settings as staff who liaise with end users in government, industry, and communities to "increase[e] the non-academic impact of research" in areas such as policy (544).

\section{Knowledge Exchange Professionals}

Shaxson et al. (2012) present KE professionals along a continuum from information intermediaries to knowledge translators, knowledge brokers and innovation brokers. Progression is marked by the shift from facilitating the dissemination of information between producers and consumers, to shaping "co-production of knowledge, social learning and innovation" (3). The progression also reflects a broadening of scope, from "informational activities" (enabling physical access to information), to relational activities (creating conditions for sense-making, decision-making, and information use), to system activities (influencing the broader systems, e.g., publishing, that shape end users' interactions with information and their ability to co-create knowledge). Van der Graaf, et al. (2018) highlight that KE and information professionals both participate in information seeking, retrieval and sharing; yet, information professionals are overlooked in KE roles, and may require more skills to understand knowledge users and their contexts. Literacy educators are similarly engaged in brokering knowledge in ways that are not adequately recognized in KE; their work leans toward relational and system oriented activities as they work with people in a variety of contexts to make sense of, respond to, and co-create knowledge. Indeed literacy educators often to translate information into accessible texts, yet they often lack access to physical and conceptual tools for information retrieval and sharing.

There is growing interest in exploring the ways in which information professionals and literacy educators, who are already embedded in the KE infrastructure, can participate in and receive recognition. Literacy educators work directly with low-literate community members in formal and informal learning settings to help them find, read, challenge and create information relevant to their daily lives; information professionals are experts in information access, organization, preservation and dissemination. The combined expertise of these two groups has the potential to enhance KE practices and outcomes (Given, et al. 2015). These professionals are well 
positioned to support researchers in the development and use of context-appropriate, equitable and diverse KE strategies and media; the retrieval of existing scholarship; approaches for working with different communities; and methods to securely store, preserve and share research. They can also bring attention to the value of KE within their respective geographical, professional and academic communities. In this, the practices of KE open up a range of new research literacies in which researchers are increasingly compelled to engage and in which literacy educators and information professionals can offer guidance.

\section{Panel Composition and Structure}

This panel brings together faculty in information science and literacy education programs and academic libraries to examine ways in which information professionals and literacy educators “broker” knowledge. Using Shaxson et al.'s (2012) model of the “K* spectrum," we examine: education, training and professional development, and innovative KE projects.

Heather O'Brien (Associate Professor, UBC iSchool) will moderate and introduce the panel. She will contextualize the $\mathrm{K}^{*}$ landscape, and present the $\mathrm{K}^{*}$ spectrum as an organizing framework for the activities and qualities that have been purported to be important for knowledge brokering (Knight \& Lightowler 2010; Phipps \& Morton 2013). This discussion will provide the context for the following focal questions for the panel:

- What training and professional development opportunities are required to enhance information professionals and literacy educators participation in the $\mathrm{K}^{*}$ spectrum?

- How might we think about KE as a curricular and pedagogical framework in library and information studies (LIS) and education programs?

- How are current professionals breaking ground in terms of the projects they are undertaking and the communities with which they engage?

Luanne Freund (Associate Professor and Director, UBC iSchool) will present an analysis of strengths and gaps in existing curricula of information schools with respect to KE and knowledge brokering roles. Her presentation will be informed by expertise in LIS learning outcomes and assessment, and a decade of teaching and research in information seeking, the design of information services and systems, and digital scholarship.

Suzanne Smythe (Associate Professor, Adult Literacy and Adult Education) will position KE as research literacy and pedagogy. She will expand on the role of literacy education in problematizing research products and processes, as well as using textual and communication strategies to make research knowledge more accessible to different audiences.

Aleha McCauley (Community Engagement Librarian, UBC Library) will describe current efforts to develop an "infohub" with UBC Library and the UBC Learning Exchange. Infohub is an online space to correlate end of research outputs such as articles, with other novel forms of dissemination such as videos; its purpose is to enhance university-community KE. She will discuss lessons learned to date, including the challenges of helping authors negotiate copyright and share their research, and designing online portals for multiple stakeholders that are inclusive, representative, and accessible to diverse communities. 
Heather De Forest (Community Scholars Librarian, SFU Library) will discuss the Community Scholars Program (CSP), an innovative collaboration of SFU Library, Vancouver Island University Library, University of Northern BC Library and supporting community organizations. CSP is facilitating and assessing the information needs of community organizations in BC and providing access to previously paywalled research to these end users. She will share her experiences of mediating publisher and community interests, and insights pertaining to the capacity required to sustain and grow CSP, including the need to help prepare graduate students and early career scholars to engage in KE.

Each panellist will speak for 10-12 minutes, with time remaining for Q\&A and discussion.

\section{Conclusion}

This panel seeks to demonstrate that information professionals and literacy educators can bridge the divide between traditional and more open and engaged scholarly practices, and support researchers in responding effectively and ethically to institutional and funding mandates. Adequate support is required for researchers to co-create knowledge with community stakeholders, to enhance traditional scholarly outputs (e.g., journal articles) through more accessible genres (e.g., visualizations, lay summaries), and to work towards the restructuring of the scholarly enterprise at a broader societal level.

Information professionals and literacy educators are well positioned to take on new roles within the $\mathrm{K}^{*}$ spectrum, and to increase capacities within the university and stakeholder communities to co-create knowledge in mutually beneficial ways. While these groups are already integrated into the research process and engaged with their communities, increased training, professional development, and recognition of their value in the KE landscape is essential for open social scholarship to move from a good idea to established practice. 


\section{Reference List:}

Acord, S. K., \& Harley, D. (2013). Credit, time, and personality: The human challenges to sharing scholarly work using Web 2.0. New Media \& Society, 15(3), 379-397, https://doi.org/10.1177/1461444812465140

Alperin, J.P., Muñoz Nieves, C., Schimanski, L., Fischman, G.E., Niles, M.T. \& McKiernan, E.C. (2018). How significant are the public dimensions of faculty work in review, promotion, and tenure documents? Humanities Commons [preprint]. http://dx.doi.org/10.17613/M6W950N35

Canadian Mental Health Association (CMHA), (2018). Knowledge Exchange: A Framework for Action by the Canadian Mental Health Association. Retrieved December 19, 2018 from https://cmha.ca/documents/knowledge-exchange-a-framework-for-action-by-the-canadianmental-health-association.

Esmail, L., Moore, E., \& Rein, A. (2015). Evaluating patient and stakeholder engagement in research: moving from theory to practice. Journal of comparative effectiveness research, 4(2), 133-145, https://doi.org/10.2217/cer.14.79

Given, L. M., Kelly, W., \& Willson, R. (2015). Bracing for impact: The role of information science in supporting societal research impact. Proceedings of the Association for Information Science and Technology, 52(1), 1-10, https://doi.org/10.1002/pra2.2015.145052010048

Harley, D., Acord, S. K., Earl-Novell, S., Lawrence, S., \& King, C. J. (2010). Assessing the Future Landscape of Scholarly Communication: An Exploration of Faculty Values and Needs in Seven Disciplines. Final Report. Center for Studies in Higher Education. University of California, Berkeley, Berkeley, CA. Retrieved from, https://cloudfront.escholarship.org/dist/prd/content/qt15x7385g/qt15x7385g.pdf

Knight, C., \& Lightowler, C. (2010). Reflections of'knowledge exchange professionals' in the social sciences: emerging opportunities and challenges for university-based knowledge brokers. Evidence \& policy: a journal of research, debate and practice, 6(4), 543-556, https://doi.org/10.1332/174426410X535891

Morrison, H. (2013). Economics of scholarly communication in transition. First Monday, 18(6). Retrieved from, http://firstmonday.org/ojs/index.php/fm/article/view/4370/3685

Nathan, L.P., Kaczmarek, M., Cheng, S., Mann, R. et al. (2017). Good for whom? Unsettling research practice. In Proceedings of the 8th International Conference on Communities and Technologies (pp. 200-297). ACM, https://doi.org/10.1145/3083671.3083685

Phipps, D., \& Morton, S. (2013). Qualities of knowledge brokers: reflections from practice. Evidence \& Policy: A Journal of Research, Debate and Practice, 9(2), 255-265, https://doi.org/10.1332/174426413X667784

Shaxson, L., Bielak, A., Ahmed, I., Brien, D., Conant, B., Fisher, C., \& Phipps, D. (2012, April). Expanding our understanding of $\mathrm{K}^{*}(\mathrm{KT}, \mathrm{KE}, \mathrm{KTT}, \mathrm{KMb}, \mathrm{KB}, \mathrm{KM}$, etc.). In A concept paper emerging from the $K^{*}$ conference held in UNU-INWEH Hamilton, ON. Retrieved from, http://inweh.unu.edu/wpcontent/uploads/2013/05/KStar ConceptPaper_FINAL_Oct29 WEBsmaller.pdf

van der Graaf, P., Cheetham, M., McCabe, K., \& Rushmer, R. (2018). Localising and tailoring research evidence helps public health decision making. Health Information \& Libraries Journal, 35(3), 202-212, https://doi.org/10.1111/hir.12219 